\title{
SÍLICA MICROCRISTALINA (TRÍPOLI) EM ROCHAS SEDIMENTARES PERMIANAS DO FLANCO LESTE DA BACIA DO PARANÁ, ESTADO DE SÃO PAULO, BRASIL
}

\author{
CLÁUDIO RICCOMINI*, LUCY GOMES SANT’ANNA** \& ARMANDO MÁRCIO COIMBRA*
}

\begin{abstract}
MICROCRYSTALLINE SILICA (TRIPOLI) IN PERMIAN SEDIMENTARY ROCKS OF THE EASTERN FLANK OF THE PARANA BASIN, SÄO PAULO STA TE, BRAZIL Microcrystalline silica occurs as tripoli, siliceous concretions and chert with microbial mats in Permian sedimentary rocks at the top of the Tatuí Formation, in the region of the Pitanga Anticline, Paraná Basin, southeastern Brazil. The tripoli is porous and mineralogically simple, composed almost entirely of aggregates of fine-grained crystals of quartz $(\sim 2 \mathrm{pm})$. The microcrystalline silica originated by the percolation of hydrothermal fluids along NE and NW faults and fractures probably during the late stages of the Paraná flood magmatism (Early Cretaceous). The introduction of silica and precipitation of quartz were contemporaneous with the dissolution of carbonate rocks. The same siliceous fluids produced a cement of euhedral quartz crystals commonly more than $5 \mathrm{pm}$ long as overgrowths on detrital grains in sandstones. The hydrothermal silicification occurred below shales and siltstones of the Taquaral Formation, which acted as a permeability barrier to the fluids.
\end{abstract}

Keywords: Microcrystalline silica, tripoli, hydrothermalism, Paraná Basin, Tatuí Formation, Paraná flood magmatism, Early Cretaceous, Brazil

RESUMO Em rochas sedimentares permianas do topo da Formação Tatuí, na região do Anticlinal de Pintanga, Estado de São Paulo, são reconhecidas ocorrências de sílica microcristalina sob a forma de tripoli, concrecões silicosas e silexitos com estruturas microbianas. A caracterizacão mineralógica dessas ocorrências permitiu verificar a predominância de agregados de cristais de quartzo microcristalino $(\sim 2 \mu \mathrm{m})$, constituindo materiais porosos. O processo genético compreendeu a ação de águas hidrotermais ao longo de falhas e fraturas de direções NE e NW, com a introdução de sílica e precipitação de quartzo concomitante à dissolução de rochas carbonáticas. A percolação desses fluidos nos arenitos produziu um cimento silicoso, formado por cristais de quartzo euedrais $(>5 \mu \mathrm{m})$, envolvendo os grãos detríticos. Adicionalmente, tem-se um controle estratigráfico, pois a silicificacão ocorreu abaixo dos folhelhos e siltitos da Formação Taquaral, que teriam atuado como barreira de permeabilidade para as águas hidrotermais. Atribui-se o hidrotermalismo aos estágios finais do magmatismo da Formação Serra Geral (Cretáceo Inferior).

Palavras-chaves: Sílica microcristalina, trípoli, hidrotermalismo, Bacia do Paraná, Formação Tatuí, Magmatismo Serra Geral, Cretáceo Inferior, Brasil

INTRODUÇÃO $\mathrm{O}$ termo trípoli foi originalmente aplicado por E. O. Hovey, em 1894, a um depósito próximo a Seneca, Missouri (EUA), pelo fato de assemelhar-se ao material composto por esqueletos silicosos de diatomáceas (diatomito) dos arredores de Trípoli, Líbia (Bradbury \& Ehrlinger 1983). Posteriormente, esta designação foi estendida a outros depósitos sedimentares, essencialmente quartzosos e friáveis, que apresentavam alguma semelhança física e/ou mineralógica com aqueles do continente africano (Harben 1983).

Vários autores (e.g. Bradbury \& Ehrlinger 1983) já ressaltaram a ausência de uma definição precisa do termo e a confusão existente em seu emprego, uma vez que depósitos com características físicas e litológicas distintas já foram classificados como trípoli. Em geral, trípoli refere-se à forma de sílica pura (média de $98-99 \%$ da composição mineralógica da rocha), de granulação fina a muito fina, constituindo materiais mais ou menos friáveis e porosos, resultantes da lixiviação intempérica de calcários silicosos ou argilosos, além de rochas silicosas calcárias (Schreiber 1978, Harben 1983). Berg \& Masters (1994) sugeriram o emprego do termo sílica microcristalina, em lugar de trípoli, para englobar todas as designações dadas às rochas friáveis compostas quase que inteiramente de cristais de quartzo submicroscópicos, a maioria deles menor do que 2 um.

A constituição essencialmente quartzosa e a granulação fina desses materiais conferem-lhes grande importância econômica, podendo ser utilizados como: massa para polimento (buffing); agente regulador (extender) de propriedades de resinas, cerâmicas, tintas e borrachas; carga (filler) em materiais plásticos; ingrediente na manufatura do cimento portland (Pickering et al. 1986), dentre outras aplicações.
De modo geral, a aplicação industrial da sílica microcristalina depende, principalmente, da pureza do material, da granulação fina e uniformidade granulométrica, dos aspectos texturais da rocha e das partículas, e também da porcentagem de óxidos e hidróxidos de ferro e/ou manganês.

As principais jazidas de sílica microcristalina ocorrem nos Estados Unidos, onde vêm sendo explorados economicamente desde o final do século passado os depósitos dos estados de Arkansas e Illinois. No Brasil não se conhecem até o momento ocorrências de trípoli. Assim, esta contribuição tem por objetivo a descrição de ocorrências de trípoli, sílica microcristalina no sentido de Berg \& Masters (1994), presentes nas rochas permianas da Formação Tatuí, aflorantes na porção leste da Bacia do Paraná no Estado de São Paulo, na região de Rio Claro e Ipeúna (Fig. 1).

CONTEXTO GEOLÓGICO E TECTÔNICO A área das ocorrências de trípoli está situada no Alto Estrutural de Pitanga. Esta estrutura tem sido relacionada a dobramentos (Washburne 1930, Almeida \& Barbosa 1953, Barbosa \& Gomes 1958), afalhamentos (Oppenheim \& Malamphy 1936, Fúlfaro et al. 1982, Sousa Filho 1983), ou a ambos os processos (Andrade \& Soares 1971). Em recente trabalho, Riccomini (1995) retomou a designação de Anticlinal de Pitanga, originalmente atribuída por Washburne (1930), considerando esta feição resultante de dobramento en echelon, associado a um binário transcorrente sinistrai de orientação geral NNW, coincidente com o Alinhamento do Rio Moji-Guaçu (Coimbra et al. 1981).

A região do Anticlinal de Pitanga possui evolução tectônica polifásicã, marcada por seis fases de intensa movimentação e 


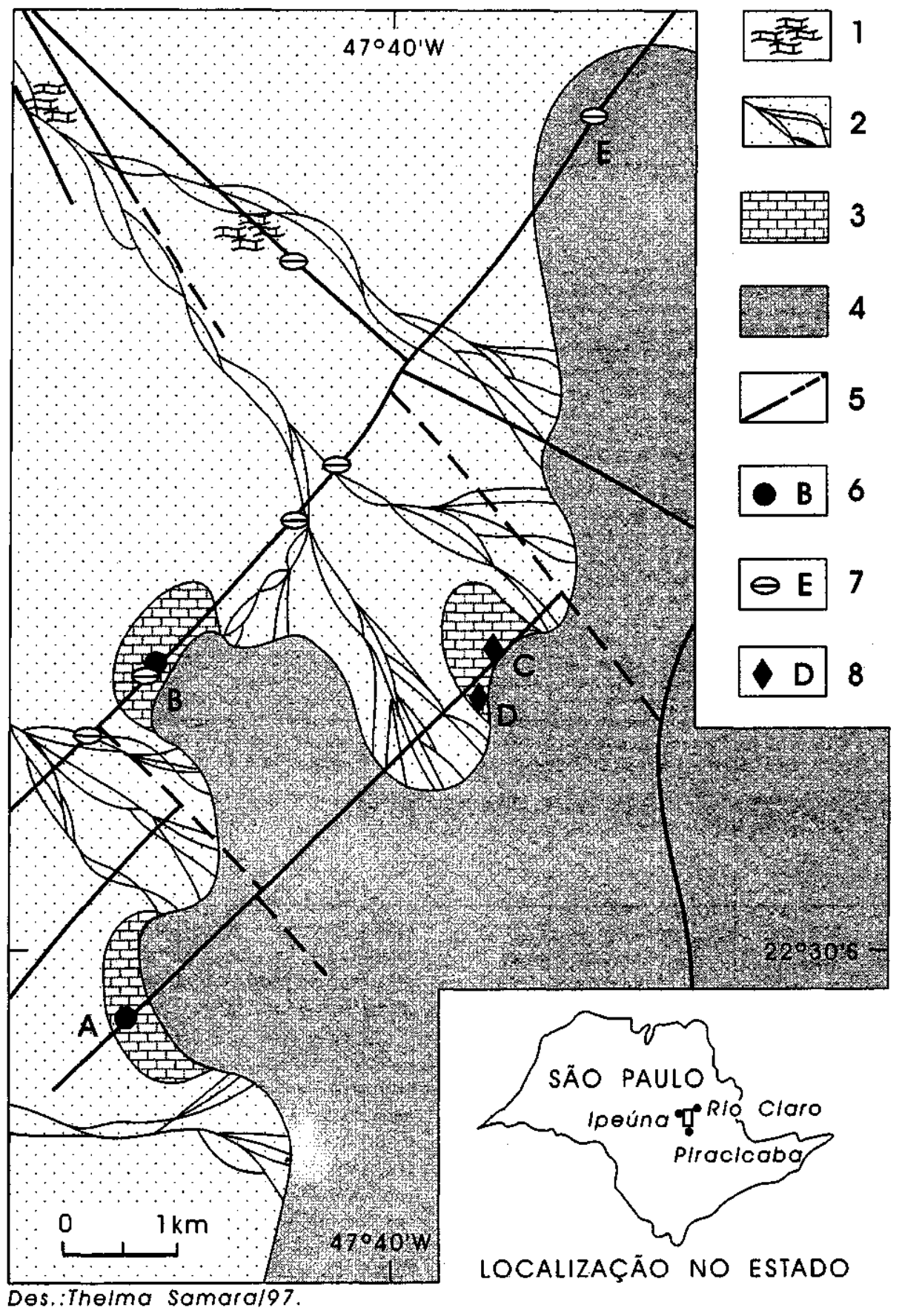

Figura 1 - Reconstituição paleogeográfica do topo da Formação Tatuí na região do Anticlinal de Pitanga: 1 - paleossolos calcíticos; 2 - arenitos de sistema fluvial a delta entrelaçado; 3 - áreas de deposição carbonática; 4 - arenitos fossilíferos (dentes e restos de barbatanas de tubarões, bivalves) e arenitos finos com hummocky cross stratification, de barras de tempestades; 5 principais falhas, inferidas quando tracejadas; 6 - ocorrências de tripoli, com letras indicando os locais referidos no texto; 7 concreções silicosas; 8 - silexitos com estruturas microbianas preservadas.

Figure 1 - Paleogeographic map of the top of the Tatuí Formation in the region of the Pitanga Anticline: 1 - calcareous paleosols; 2 - fluvial and braided delta sandstones; 3 - areas of carbonate deposition; 4 -fossiliferous sandstones (shark teeth and spines, bivalves) and fine-grained sandstones with hummocky cross stratification (tempestite bars); 5 - main faults, dashed where inferred; 6 - tripoli occurrences, with letters as mentioned in the text; 7 - siliceous concretions; 8 chert with preserved microbial structures.

deformação (Riccomini 1992, 1995): 1) eventos sísmicos sinsedimentares, no Permiano Superior a Triássico Inferior; 2) extensão NE-SW e, secundariamente, NW-SE, com a colocação de diques e sills de diabásio da Formação Serra Geral, no Cretáceo Inferior; 3) transcorrência dextral com compressão NW-SE e extensão NE-SW, com manifestação inicial no Cretáceo Inferior, penecontemporânea à fase tardia do magmatismo Serra Geral; 4) compressão NE-SW; 5 e 6) inicialmente extensão e posteriormente compressão, de direção NW-SE, quaternárias e ambas com caráter neotectônico.

A situação estrutural favoreceu a exposição de significativa parcela da coluna estratigráfica da Bacia do Paraná. Do centro para as bordas do Anticlinal de Pitanga ocorrem rochas sedi- 
mentares neopaleozóicas dos grupos Tubarão (Subgrupo Itararé; Formação Tatuí) e Passa Dois (formações Taquaral e Assistência do Subgrupo Irati; Formação Corumbataí), além de rochas mesozóicas do Grupo São Bento (formações Pirambóia, Serra Geral e Botucatu). Estas unidades são recobertas pelos depósitos cenozóicos enfeixados na Formação Rio Claro e coberturas coluviais e aluviais mais recentes.

As ocorrências de trípoli estão estratigraficamente situadas no topo da Formação Tatuí (Permiano), imediatamente abaixo do seu contato com os folhelhos cinzentos da Formação Taquaral (no sentido de Hachiro et al 1993). Nessa mesma posição estratigráfica ocorrem lateralmente: a) arenitos conglomeráticos amarelados, por vezes com estratificação cruzada acanalada, de origem fluvial; b) arenitos finos acinzentados com vênulas e concreções de calcita, com aspecto brechóide localizado, correspondendo a horizontes pedogenéticos do tipo calcrete; c) arenitos maciços contendo dentes e restos de barbatanas de tubarões, raros bivalves não articulados e seixos de silexitos, sendo interpretados como retrabalhamento costeiro dos depósitos fluviais; d) arenitos finos com estratificações cruzadas truncadas por ondas e humtnocky cross stratification, representando tempestitos; e) silexitos preservando estruturas orgânicas, provavelmente relacionadas à atividade microbiana (esteiras microbianas). Nos arenitos finos são observadas concreç̃es silicosas, com formas discóides centimétricas (até 4-5 $\mathrm{cm}$ de diâmetro por 3-4 $\mathrm{cm}$ de espessura). Os litotipos descritos em a) e c) são conhecidos pela designação de Conglomerado Pitanga (Soares 1991).

Essas variações laterais de fácies ocorrem em um intervalo não superior a $1 \mathrm{~m}$ de espessura e correspondem a um trato de mar baixo da unidade Tatuí, com a implantação de sistemas fluviais, transicionais e marinhos costeiros retrabalhados por ondas de tempestades.

Com base na distribuição lateral e vertical dessas diferentes fácies pode ser elaborado um esboço paleogeográfico do topo da Formação Tatuí, na sua interface com a Formação Taquaral (Fig. 1). Nele pode ser verificada a extensão dos depósitos fluviais, provavelmente relacionados a deltas entrelacados (braided deltas), e que as ocorrências de trípoli e de silexitos com estruturas de esteiras microbianas situam-se em áreas onde originalmente ocorreu deposição carbonática, protegida do aporte terrígeno, em zonas de interlobos deltaicos, provavelmente lagunares. Adicionalmente, as ocorrências de trípoli, concreções silicosas e silexitos encontram-se dispostas principalmente ao longo de fraturas de direção N40-50E, subverticais.

MATERIAIS E MÉTODOS ANALÍTICOS O estudo mineralógico baseou-se, inicialmente, em análises de rocha total via difração de raios $\mathrm{X}$, utilizando-se o equipamento VEB Cari Zeiss JENA do Departamento de Mineralogia e Petrologia do Instituto de Geociências da Universidade de São Paulo (USP), operando com $40 \mathrm{kV}, 20 \mathrm{~mA}$, radiação CuKa, filtro de Ni e velocidade do goniómetro de $2^{\circ} 20 / \mathrm{min}$. Para todas as amostras totais foram obtidos difratogramas rotineiros, de $3^{\circ}$ a $65^{\circ} 2 \theta$, sem tratamento prévio.

Para a complementação dos estudos, foi efetuada a caracterização textural dos sedimentos e morfológica dos grãos individuais via microscopia eletrônica de varredura (MEV), com microanálise por energia dispersiva (EDS) acoplada. Para tanto foi utilizado o aparelho da marca JEOL, modelo JSMT330A, instalado no Núcleo de Pesquisa em Geoquímica e Geofísica da Litosfera (NUPEGEL) da USP.

\section{GEOLOGIA E MINERALOGIA DAS OCORRÊNCIAS}

O trípoli ocorre sob a forma de camadas de espessuras decimétricas. Embora com persistência lateral e espessura relativamente constante em escala de afloramento, as camadas são descontínuas ao nível regional. Na Fazenda Santo António do Paraíso (Local A, Fig. 1), situada a cerca de $3,8 \mathrm{~km}$ a nordeste da localidade de Paraisolândia (Município de Charqueada), ocorrem duas camadas de trípoli, a superior com 25 $\mathrm{cm}$ e a inferior com $5-10 \mathrm{~cm}$ de espessura, separadas por 30 $\mathrm{cm}$ de arenitos finos (Fig. 2A). Na Fazenda Biri, a cerca de $5,5 \mathrm{~km}$ a sudeste de Ipeuna (Local B, Fig. 1), a camada de trípoli é única, com cerca de $40 \mathrm{~cm}$ de espessura, e encontra-se sotoposta a uma camada areno-conglomerática com espessura de 30-40 cm, esta assinalando a interface entre as formações Tatuí e Taquaral (Fig. 2B).

As camadas de trípoli são esbranquiçadas, localmente com variaç̃es para amarelo ou marrom devido à alteração intempérica; a estrutura é maciça a incipientemente laminada e, em geral, apresentam-se muito friáveis e com predominância da fração silte ao exame táctil. Os estudos laboratoriais revelaram que o trípoli é composto quase que integralmente por quartzo, como demonstra o difratograma de raios $\mathrm{X}$ de amostra total (Fig. 3A). Em MEV foi possível verificar que a rocha é constituída por agregados (Fig. 3B), com diâmetro médio da ordem de $10 \mu \mathrm{m}$, de cristais euedrais a subedrais de quartzo de granulação fina (em média de 0,5 a $2 \mu \mathrm{m}$ ) (Fig. 3C) e, subordinadamente, por cristais de quartzo maiores, com cerca de $5 \mu \mathrm{m}$; nestes sedimentos, o quartzo está comumente associado a óxidos de Mn, estes detectados por EDS (Fig. 3D).

Os agregados quartzosos compõem uma massa fina e muito porosa, onde encontram-se esparsamente disseminados grãos detríticos de quartzo, feldspato e mica, além de restos de fragmentos orgânicos silicificados.

A sílica microcristalina ocorre ainda sob a forma de nódulos e concreções de sílex disseminados nos arenitos finos das porções de topo da Formação Tatuí. Localmente (Locais $\mathrm{C}$ e D, Fig. 1) ocorre uma camada de silexito com espessura métrica, a qual representa antigo depósito carbonático com esteiras microbianas, agora silicificadas, como indicam as estruturas sedimentares ainda preservadas (Fig. 4A). O difratograma de raios $\mathrm{X}$ de amostra total deste sedimento também demonstra sua composição essencialmente silicosa (Fig. 4B).

$\mathrm{O}$ estudo textural de arenitos finos da Formação Tatuí, aflorantes no leito do Rio da Cabeça (Local E, Fig. 1), permitiu o reconhecimento e a caracterização, de forma mais detalhada, das relações genéticas envolvidas na silicificação desta unidade. Estes sedimentos são constituídos essencialmente por quartzo e feldspato (Fig. 5), cuja origem detrítica é atestada pelas formas arredondadas dos grãos (Fig. 6A). Os espectros de EDS das figuras $6 \mathrm{~B}$ e $6 \mathrm{C}$ demonstram, respectivamente, a presença de grãos de feldspato potássico no sedimento e a pureza do cimento silicoso. A silicificação nos depósitos da Formação Tatuí produziu o revestimento total ou parcial dos grãos detríticos por cristais finos e euédricos de quartzo (Fig. 6A). Estes cristais euédricos de quartzo têm como base de crescimento as superfícies dos grãos detríticos e seu desenvolvimento se dá em direção aos poros originais do sedimento, como observado no detalhe da figura 6D.

Nas fotomicrografias de MEV da figura 7 é possível notar que a silicificação permitiu a cristalização tanto de cristais euédricos, bipiramidados, com granulação maior do que 5 um, quanto de cristais menores e com hábitos subédricos a anédricos. As análises por MEV revelaram ainda uma segunda etapa de preenchimento dos poros dos sedimentos, dada pela presença de cristais euédricos de albita (Figs. 6A, 8A), cujo desenvolvimento é posterior ao evento de silicificação, uma vez que a albita preenche os poros deixados pela sílica microcristalina. No detalhe da figura $8 \mathrm{~B}$ nota-se a relação textural dos cristais de albita com o cimento silicoso e, no espectro de EDS da figura 8C, a composição da albita.

CONSIDERAÇÕES SOBRE A GÊNESE Em geral, a origem dos depósitos de trípoli tem sido atribuída a longos 

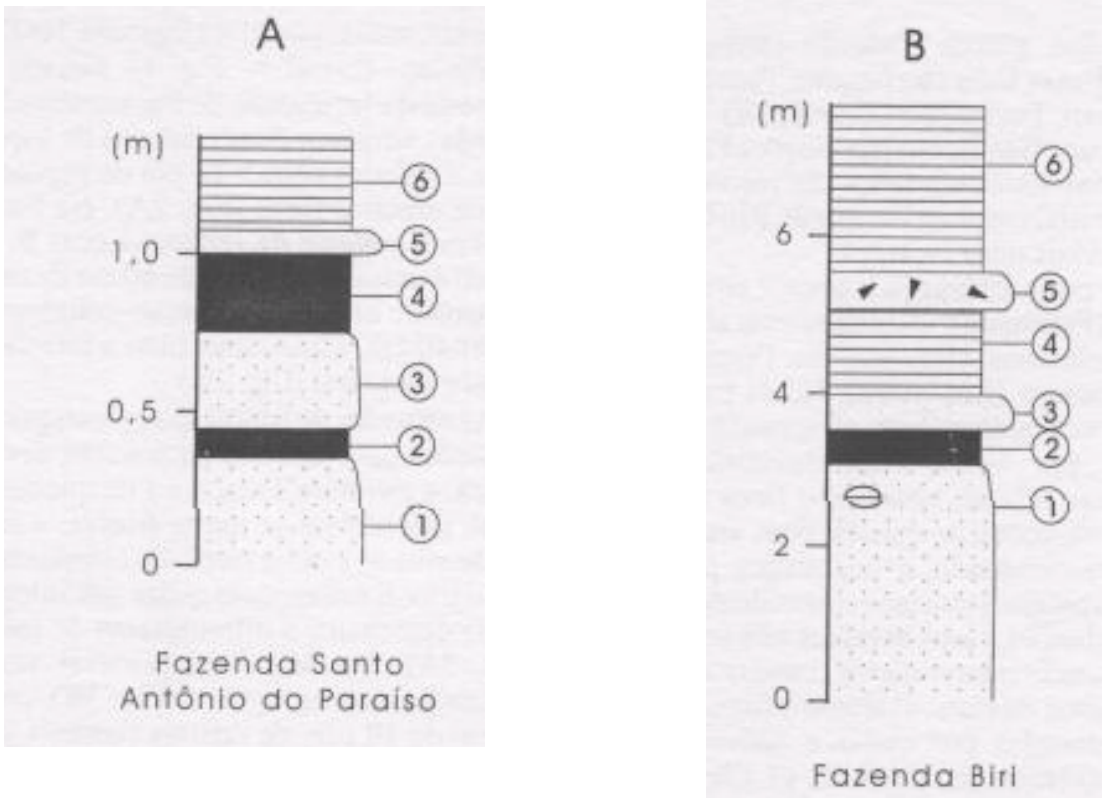

Figura 2 - (A) Seção colunar na Fazenda Santo Antônio do Paraíso: Formação Tatuí (1 e 3 - arenitos finos siltosos maciços, 2 e 4 - trípoli, 5 - arenitos conglomeráticos maciços); Formação Taquaral (6 -folhelhos e siltitos cinzentos). (B) Seção colunar na Fazenda Biri: Formação Tatui (l - arenitos finos siltosos maciços com concreções silicosas discóides, 2 - trípoli, 3 - arenitos conglomeráticos maciços); Formação Taquaral (4 e 6 -folhelhos e siltitos cinzentos, 5 - arenito com dentes e restos de barbatanas de tubarões).

Figure 2 - (A) Columnar section, Santo António do Paraíso farm: Tatuí Formation (1 and 3 - massive fine-grained silty sandstones, 2 and 4 - tripoli, 5 - massive conglomeratic sandstones); Taquaral Formation (6 - gray shales and siltstones). (B) Columnar section, Biri farm: Tatuí Formation (1 - massive fine-grained silty sandstones with discoidal siliceous concretions, 2 - tripoli, 3 - massive conglomeratic sandstones); Taquaral Formation (4 and 6 -gray shales and siltstones, 5 sandstone with shark teeths and spines).
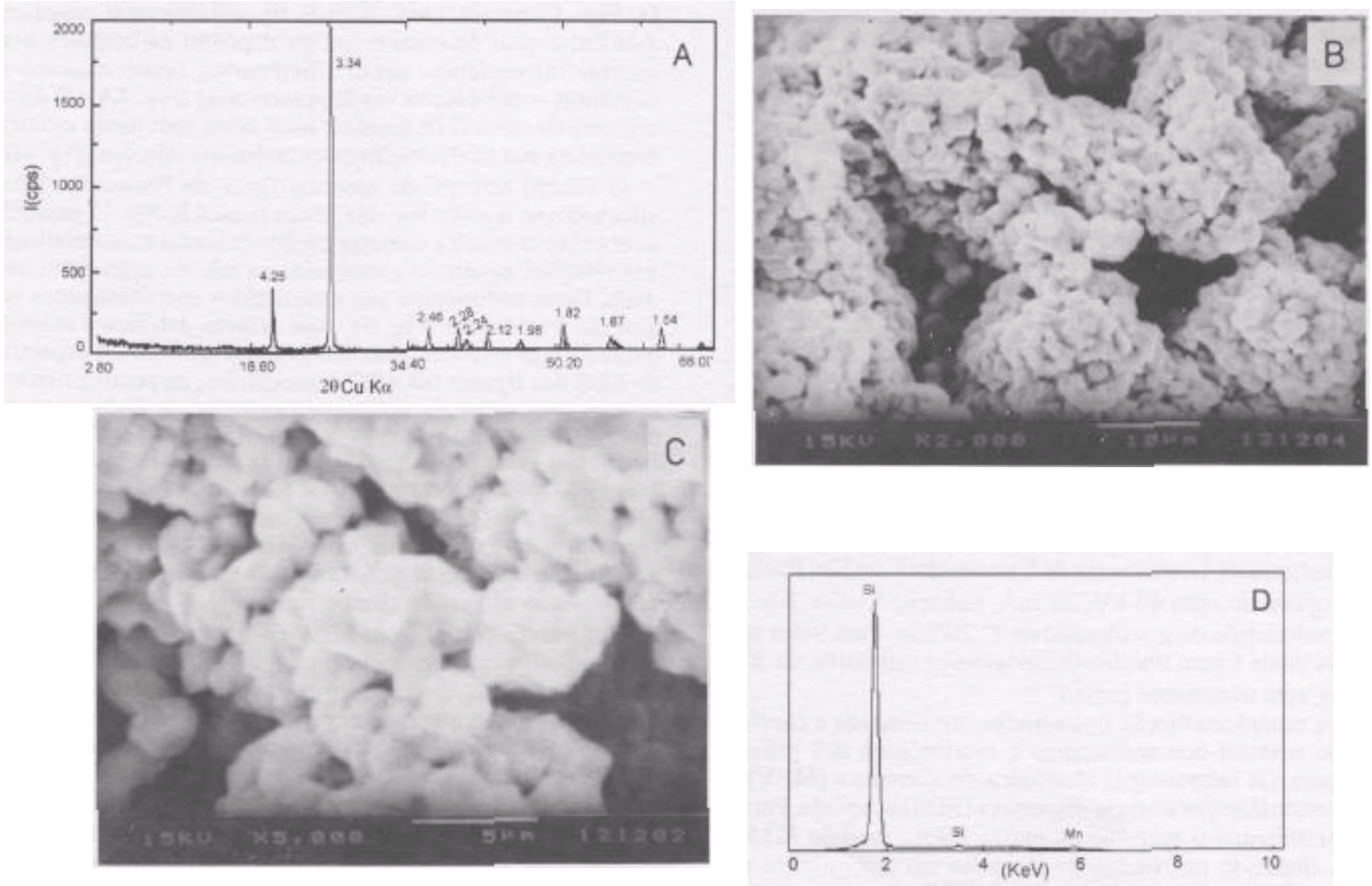

Figura 3 - Trípoli da Formação Tatuí: (A) Difrato grama de raios X obtido para amostra total do trípoli (no gráfico está indicada a indexação dos picos, com valores em angstrom A). Fotomicrografias de MEV ilustrando o aspecto geral do trípoli (B) e, no detalhe (C), a morfologia dos cristais de quartzo. (D) Espectro de EDS obtido na porção central da fotomicrografia C.

Figure 3 - Tripoli, Tatuí Formation: (A) X-ray diffraction diagram of total sample (main peaks indexed, in A ). SEM photomicrographs showing the general aspect of the tripoli (B) and, in detail (C), the morphology of the quartz crystals. (D) EDS spectrum of the central part of the area shown in C. 

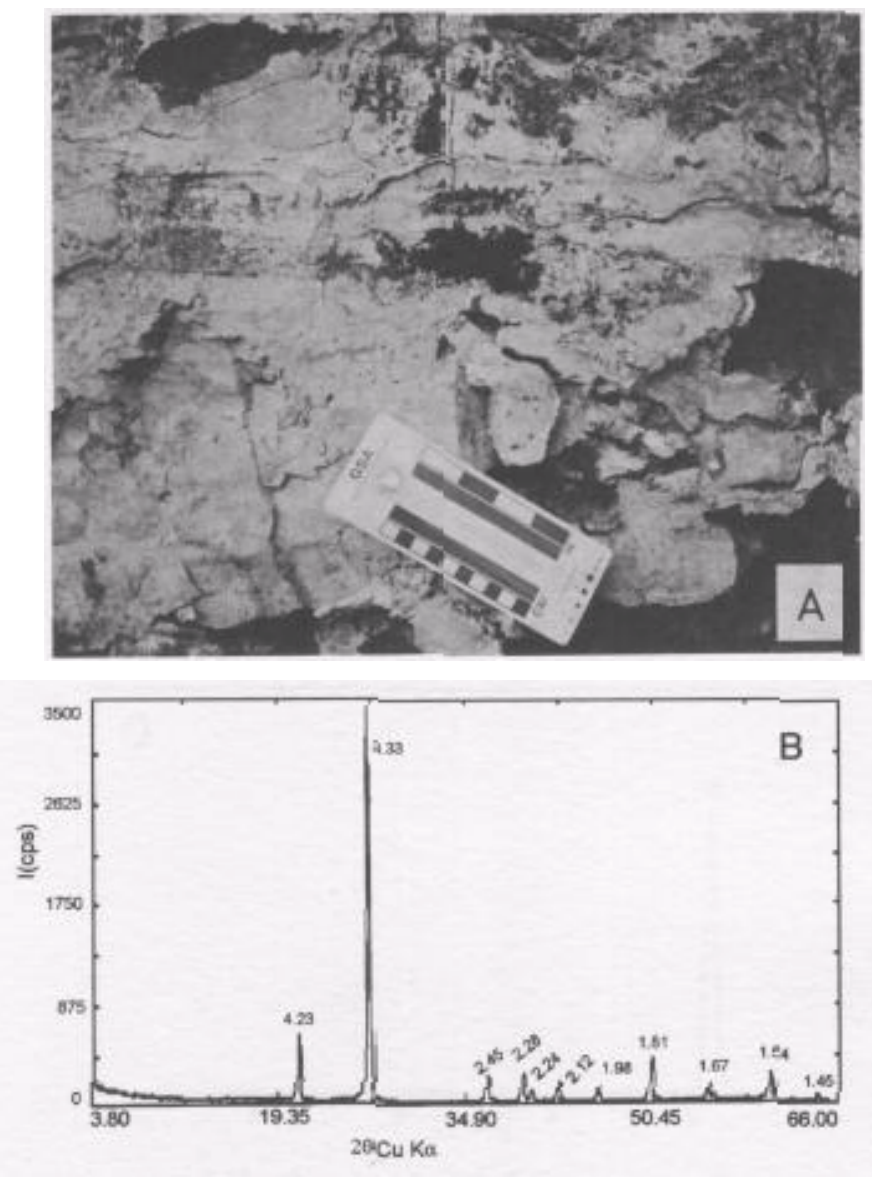

Figura 4 - Silexito da Formação Tatuí (Local D, Fig. 1) : (A) Aspecto geral da camada onde estão preservadas estruturas microbianas. (B) Difratograma de raios $X$ obtido para amostra total do silexito (no gráfico está indicada a indexação dos picos, com valores em angstrom $\AA$ ).

Figure 4 - Chert, Tatuí Formation (Site D, Fig. 1): (A) General aspect of the layer with preserved microbial structures. (B) X-ray diffraction diagram of total sarnple (main peaks indexed, in A ).

Figura 5 - Difratograma de raios X obtido para amostra total de arenito da Formação Tatuí (no gráfico está indicada a

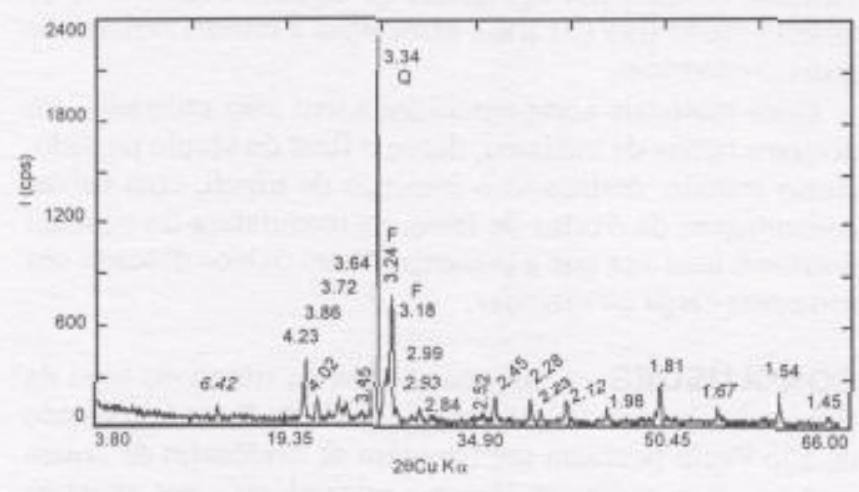

indexação dos picos, com valores em angstrom $\AA$ ) ( $Q$ quartzo, $F$-feldspato).

Figure 5 - X-ray diffraction diagram of sandstone of the Tatuí Formation (total sample; main peaks indexed, in $\mathrm{A})(\mathrm{Q}$ - quartz, $\mathrm{F}$ - feldspar). períodos de lixiviação de calcários silicosos e/ou cherts carbonáticos, sob condições superficiais ou próximas à superficie (e.g. Bradbury \& Ehrlinger 1983). No entanto, Berg \& Masters (1994), baseando-se em diversas evidências texturais e geoquímicas, apontaram origem hidrotermal para alguns depósitos de sílica microcristalina na parte sul do Estado de Illinois, EUA.

Os estudos realizados até o momento nos sedimentos da Formação Tatuí permitem também associar o processo genético de cristalização da sílica microcristalina desta unidade a fenómenos hidrotermais. Esta hipótese está baseada nas características mineralógicas da sílica microcristalina e forma de ocorrência dos depósitos, sendo elas: a) presença de faces cristalinas e forma euédrica dos cristais de quartzo que compõem a sílica microcristalina, sugerindo cristalização direta a partir de soluções silicosas; b) cristais de quartzo euédricos com eixo cristalográfico $c$ aproximadamente ortogonal à superfície que serviu de base para o seu crescimento, indicando, segundo Fournier (1985), que sua precipitação ocorreu em espaços abertos, diretamente a partir das soluções hidrotermais; c) relação textural do revestimento de grãos detríticos por quartzo fino euédrico; d) falta de continuidade lateral dos depósitos de sílica microcristalina; e e) distribuição das ocorrências ao longo de fraturas, provavelmente ativas durante a fase de extensão NE-SW e, secundariamente, NW-SE, do Cretáceo Inferior.

Estes fatores são todos considerados como fundamentais na interpretação da origem hidrotermal da sílica microcristalina (Berg \& Masters 1994), sendo raros os casos nos quais evidências tão convergentes estão presentes em um único depósito.

A exemplo dos depósitos norte-americanos, o possível controle litológico dos sedimentos na percolação das águas hidrotermais implicaria na não continuidade lateral da sílica microcristalina em um nível estratigráfico. Por outro lado, esta continuidade seria esperada caso a origem da sílica microcristalina estivesse relacionada à deposição primária na bacia sedimentar ou, ainda, à lixiviação intempérica ao longo de um plano de discordância ou superfície topográfica.

Assim, tendo em vista os dados geológicos e mineralógicos obtidos neste estudo, entende-se que o processo hidrotermal permitiu a introdução de sílica no sistema representado pelos sedimentos da Formação Tatuí, a qual, com a diminuição da temperatura, cristalizou-se como cristais de quartzo, diretamente da solução, na superfície dos grãos detríticos. A textura fina dos cristais de quartzo sugere a presença de soluções com elevadas concentrações de sílica e alta taxa de precipitação (Folk \& Pittmann 1972, Mussa \& Coimbra 1984).

Embora os depósitos carbonáticos estejam pouco preservados no topo da Formação Tatuí, a presença de estruturas relacionadas com esteiras microbianas e a própria reconstituição paleogeográfica da unidade (Fig. 1) sugerem que as fácies calcárias tenham sido originalmente mais extensas. É possível que o hidrotermalismo tenha favorecido e permitido a introdução de sílica concomitantemente com a dissolução de carbonatos (Berg \& Masters 1994), onde existentes, explicando assim a preservação de estruturas orgânicas e de fragmentos orgânicos em sedimentos constituídos quase que inteiramente por sílica microcristalina e raros grãos detríticos.

A fonte das águas hidrotermais para a silicificação da Formação Tatuí pode ser preliminarmente atribuída aos estágios finais do magmatismo Serra Geral. Este evento de grandes proporções, ocorrido no Cretáceo Inferior (Turner et al. 1994), afetou de diferentes formas os sedimentos da Bacia do Paraná (e.g. Leinz 1937, Farjallat \& Suguio 1966, Landim \& Poeschl 1967,Girardi et al. 1978, Hachiro et al. 1994). Estemagmatismo tem presença marcante na região estudada, no tadamente sob a forma de sills, de espessuras até decamétricas, 

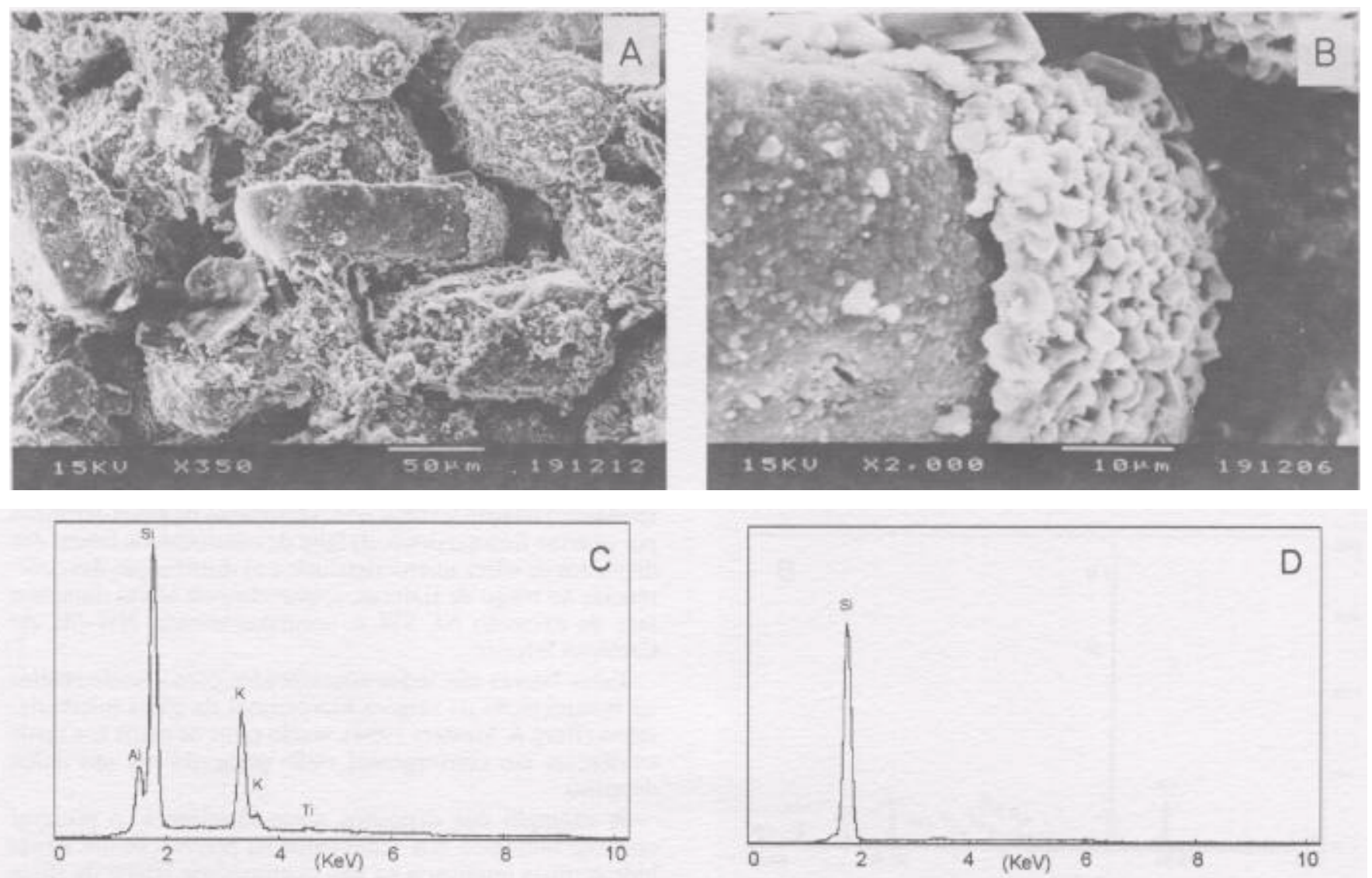

Figura 6 - Arenito da Formação Tatuí: (A) Aspecto geral da rocha, destacando-se a presença de grãos arredondados de quartzo e feldspato e a porosidade. (B) Detalhe da porção central da fotomicrografia A, ilustrando o revestimento de grão detrítico por cristais de quartzo. (C) e (D) Espectros de EDS obtidos, respectivamente, para o grão de feldspato da porção central da fotomicrografia A e para os cristais de quartzo de revestimento de grão da fotomicrografia $B$.

Figure 6 - Sandstone, Tatuí Formation: (A) General aspect of the rock showing porosity and presence of rounded grains of quartz and feldspar. (B) Detail of the central part of A showing quartz overgrowths on detrital grain. (C) EDS spectra of a grain of feldspar in the central part of A. (D) EDS spectrum of quartz of the overgrowth of the grain of photomicrography B.

frequentes na porção central do Anticlinal de Pitanga, onde encontram-se alojados preferencialmente em rochas do Subgrupo Irati.

A presença de albita nos sedimentos da Formação Tatuí ainda não pode ser plenamente esclarecida, embora uma análise preliminar pareça descartar a origem diagenética para este mineral, uma vez que não foram observadas feições de sobrecrescimento secundário (v.g. De Ros 1987). Por outro lado, o crescimento de cristais euédricos em poros intergranulares permite formular a hipótese inicial de origem hidrotermal, a partir de fluidos alcalinos. Estudos futuros de análise de fácies, amparados em dados geoquímicos, poderão elucidar esta segunda fase de eventos pós-sedimentares na Formação Tatuí.

Em síntese, a silicificação hidrotermal da Formação Tatuí possui controles estrutural (percolação das soluções hidrotermais ao longo de falhas e fraturas), litológico (substituição de calcários) e estratigráfico (silicificação abaixo dos folhelhos e siltitos da Formação Taquaral, que teriam atuado como barreira de permeabilidade para os fluídos hidrotermais).

POTENCIAL PARA USO INDUSTRIAL A MEV é uma ferramenta fundamental na caracterização textural do trípoli e, adicionalmente, permite a identificação dos melhores usos e aplicações tecnológicas do material, em função das texturas e características físicas observadas (Keller 1978).
A comparação das texturas do trípoli da Formação Tatuí com aquelas das principais ocorrências mundiais mostra uma similaridade com os depósitos típicos da região de Seneca, no Estado de Missouri, EUA (Keller 1978). Nestes, o trípoli é formado também por agregados $(5-10 \mu \mathrm{m}$ de diâmetro) de quartzo muito fino $(>1 \mu \mathrm{m})$, associados a cristais maiores de quartzo euédricos.

Estes materiais norte-americanos têm sido utilizados em diversos ramos da indústria, desde o final do século passado. Nesse sentido, destaca-se o emprego de trípoli, com baixas porcentagens de óxidos de ferro, na manufatura do cimento portland, uma vez que a presença destes óxidos descarta seu uso como carga ou extender.

CONCLUSÕES As ocorrências de trípoli do topo da Formação Tatuí no flanco leste da Bacia do Paraná no Estado de São Paulo possuem um conjunto de evidências de ordem estratigráfica, sedimentológica e mineralógica que apontam para uma origem hidrotermal dos depósitos. O processo genético principal envolveu a ação de soluções hidrotermais, ricas em sílica, provavelmente de origem magmática tardia. A sílica assim introduzida nas rochas sedimentares da Formação Tatuí precipitou-se, concomitantemente à dissolução de carbonato, por abaixamento de temperatura. 

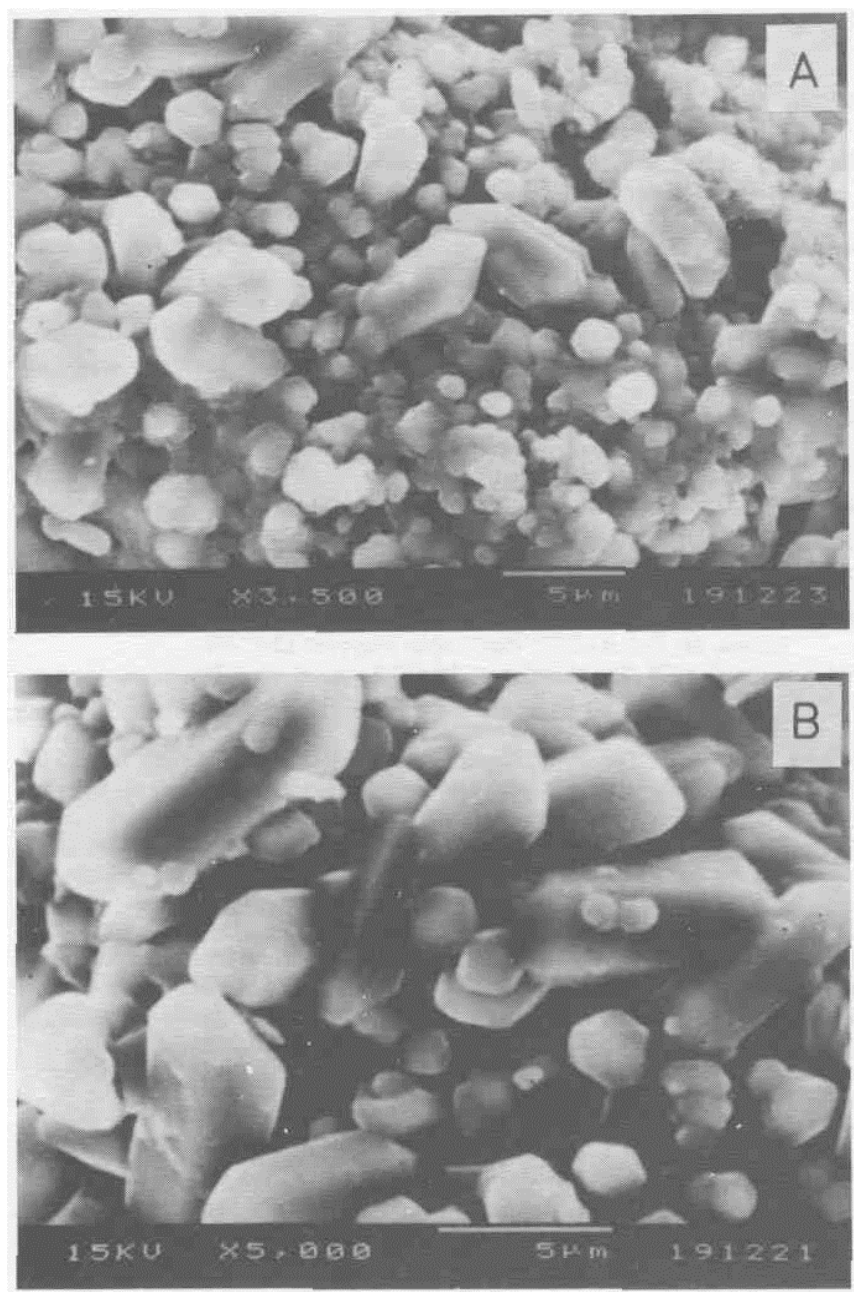

Figura 7 - Fotomicrografias de MEV mostrando cristais de quartzo euédricos a anédricos (A) e, no detalhe (B), a morfologia bipiramidal dos cristais de quartzo maiores do que $5 \mu \mathrm{m}$.

Figure 7 - SEM photomicrographs showing euhedral and anhedral crystals of quartz (A) and, in detail (B), the dipyramidal morphology of the coarser crystals of quartz $(>5 \mu \mathrm{m})$

Atribui-se aos estágios finais do magmatismo da Formação Serra Geral a origem das águas hidrotermais, o que permite situar no Cretáceo Inferior o processo de formação do trípoli.

A ocorrência de trípoli na Formação Tatuí demonstra a importância econômica do hidrotermalismo eocretáceo e encoraja estudos futuros, por se situar em uma região próxima a pólos industriais com diferentes ramos de atividade. Assim, ainda que a área de ocorrência estudada seja de pequena extensão, e que a origem hidrotermal apontada mostre a predominância de depósitos irregulares e pouco contínuos, estudos de detalhe associados a investigações em subsuperfície poderão indicar outras áreas de silicificação das unidades permianas da Bacia do Paraná, no Estado de São Paulo e regiões adjacentes.

\section{Agradecimentos}

Os autores externam seus agradecimentos ao Núcleo de Pesquisa em Geoquímica e Geofísica da Litosfera (NUPEGEL), da Universidade de São
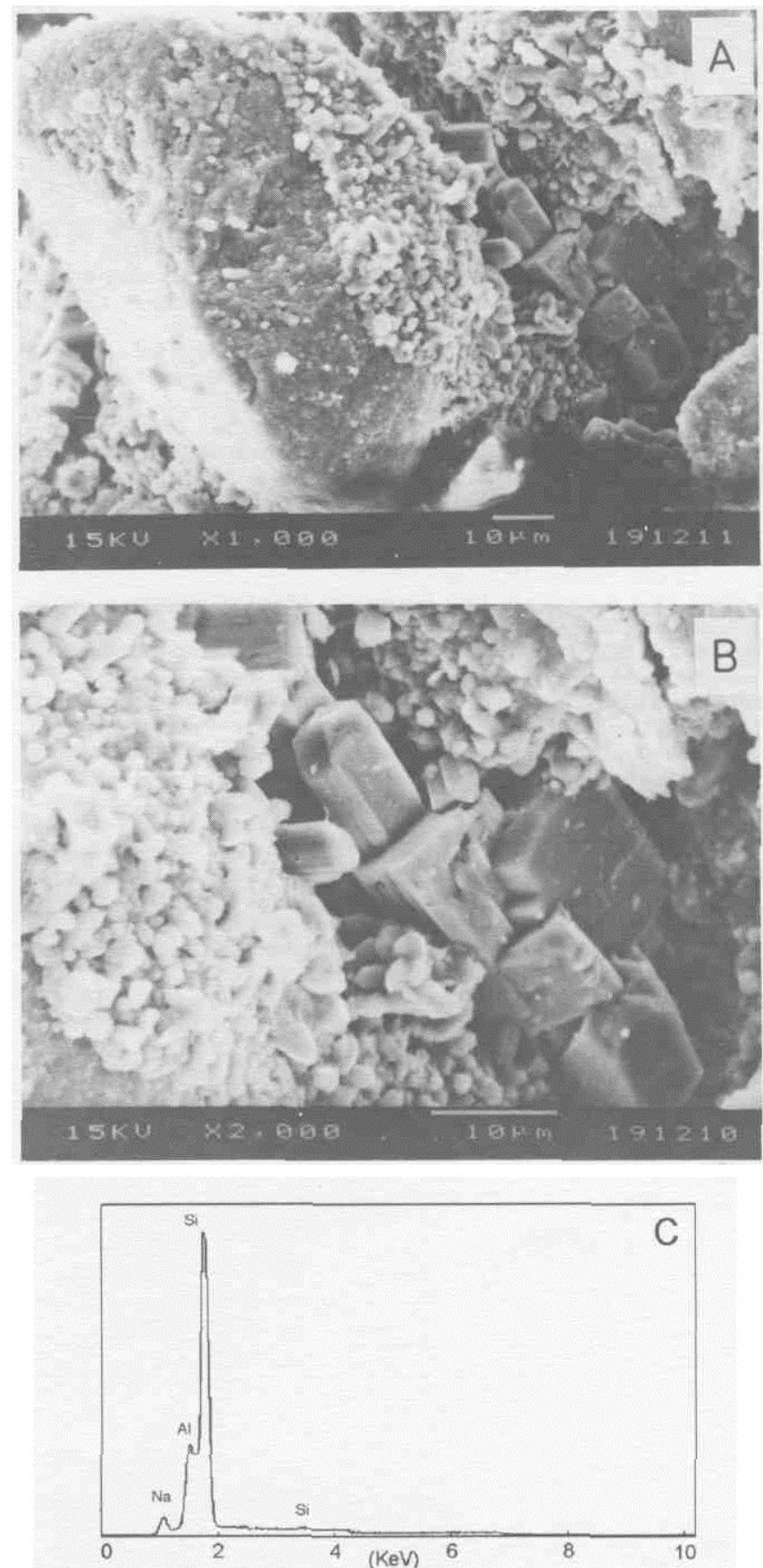

Figura 8 - Fotomicrografias de MEV de arenito da Formação Tatuí, contendo cristais de albita (A) crescidos na porosidade originada pela silicificação. (B) Detalhe dos cristais de albita. (C) Espectro de EDS obtido para a albita da fotomicrografia $B$.

Figure 8 - SEM photomicrographs of sandstone of the Tatuí Formation showing albite crystals growing (A) in the secondary porosity generated by silicification. (B) Detail of the albite crystals. (C) EDS spectrum of the albite in $\mathrm{B}$.

Paulo, pelas facilidades laboratoriais oferecidas, ao Prof. Dr. Thomas R. Fairchild (IG-USP) pelas sugestões e revisão do inglês, e a Sra. Thelma Samara (IG-USP) pela confecção de parte das ilustrações 


\section{REFERÊNCIAS}

Almeida, F.F.M. \& Barbosa, O. 1953. Geologia das quadrículas de Piracicabae Rio Claro, Estado de São Paulo. Rio de Janeiro, DNPM/DGM, 96 p. (Boletim 143)

Andrade, S.M. \& Soares, P.C. 1971. Geologia do centro-leste do Estado de São Paulo. PETROBRÁS/DESUL-SEGES. (Relatório 407)

Barbosa, O. \& Gomes, F.A. 1958. Pesquisa de petróleo na bacia do Rio Corumbataí. Rio de Janeiro, DNPM/DGM, 40 p. (Boletim 171)

Berg, R.B \& Masters, 'j.M. 1994. Geology of microcrystalline sílica (tripoli) deposits, southernmost Illinois. Illinois State Geological Survel, Circular, $555,89 \mathrm{p}$.

Bradbury, J.C. \& Ehrlinger, H.P. 1983. Tripoli. In: Lefond, S.J. (ed.) Industrial Minerais and Rocks. New York, American Instituto of Mining, Metallurgical and Petroleum Engineers, p.1209-1218

Coimbra, A.M.; Brandt Neto, M.; Coutinho, J.M.V. 1981. Silicificação dos arenitos da Formação Bauru no Estado de São Paulo. In: SBG/ Núcleo São Paulo, A Formação Bauru no Estado de São Paulo e regiões adjacentes. São Paulo, Coletânea de trabalhos e debates, 103-115

De Ros, L.F. 1987. Petrologia e características de reservatório da Formação Sergi (Jurássico) no Campo de Sesmaria, Bacia do Recôncavo, Brasil. Ciência, Técnica, Petróleo, 19:107 p.

Farjallat, J.E.S. \& Suguio, K. 1966. Observações sobre a zeolitização em basalto e arenito, Nioaque, Mato Grosso. Bol. Soe Bros. Geol, 15:51-58

Folk, R.L. \& Pittmann, J. 1972. Length-slow chalcedony: a new testament for vanished evaporites. J. Sed. Petrol, 41:1045-1058

Fournier, R.0.1985. The behaviour of sílica in hydrothermal solutions. In: Berger, B.R. \& Bethke, P.M. (eds.). 1985. Geology and geochemistry ofepithermal systems. Chelsea, Society of Economic Geologists, Reviews in Economic Geology, v.2, p. 45-61

Fúlfaro, V.J.; Saad, A.R.; Santos, M.V.; Vianna, R.B. 1982. Compartimentação e evolução tectônica da Bacia do Paraná. São Paulo, PAULIPETRO/CESP/IPT, p. 75-142. (Relatório)

Girardi, A.V.; Melfi, A.J.; Amaral, S.E. 1978. Efeitos termais associados aos diabásios mesozóicos da Bacia do Paraná. Bol. IG-USP, 9:47-55

Hachiro, J.; Coimbra, A.M.; Matos, S.F.L. 1993.0 caráter cronoestratográfico da Unidade Irati. In: IGCE/UNESP, Simpósio sobre Cronoestratigrafia da Bacia do Paraná, 1, Rio Claro, Resumos, 62-63

Hachiro, J.; Coutinho, J.M.V.; Coimbra, A.M. 1994. Efeitos metamórficos de instrusivas básicas em sedimentos do Subgrupo Irati (Rio Aporé - MS). In: SBG/ Núcleo Brasília, Simpósio de Geologia do Centro-Oeste, 4, Brasília, Anais, 64-65

Harben, P. 1983. Tripoli and novaculite -the little known relations. Industrial Minerais, 184:28-32
Keller, W.D. 1978. Textures of tripoli illustrated by scanning electron micrographs. Econ. Geol., 73:442-446

Landim, P.M.B. \& Poeschl, A. 1967. Sulfetos na zona de contato entre diabásio e sedimentos da Formação Corumbataí (Piracicaba, SP). Eng. Min. Met. 45:19-21

Leinz, V. 1937. Observações nos contactos de diabásio com sedimentos. Rio de Janeiro, SOM, p. 13-16. (Notas Preliminares e Estudos 7)

Mussa, D. \& Coimbra, A.M. 1984. Método de estudo tafonômico aplicado a lignispécies permianos da Bacia do Paraná. An. Acad. Bros. CL, 56:85-10

Oppenheim, V. \& Malamphy, M.C. 1936. Notas sobre a tectônica da área São Pedro-Xarqueada. Rio de Janeiro, SFPM, 12 p. (Avulso 7)

Pickering, S.M., Jr.; Avant, A.J.; Salomon, A.J.; Fox, W.R. 1986. Southern Illinois white tripoli as filler, extender and abrasive. Mining Engineering, 38:1125-1127

Riccomini, C. 1995. Tectonismo gerador e deformador dos depósitos sedimentares pós-gondvânicos da porção centro-oriental do Estado de São Paulo e áreas vizinhas. Inst. de Geociências, Universidade de São Paulo, São Paulo, Tese de Livre-Docência, 100 p.

Riccomini, C. 1992. Estilos estruturais da região do Domo de Pitanga, Bacia do Paraná, SP. Boi. IG-USP, Publicação Especial, 12:93-94

Schreiber, B.C. 1978. Tripoli, tripolite. In: Fairbridge, R. W. \& Bourgeois, J. (eds). 1978. The encyclopedia of sedimentology. Stroudsburg, Dowden, Hutchinson and Ross, p. 821

Soares, P.C. 1991. Tectônica sinsedimentar cíclica na Bacia do Paraná controles. Departamento de Geologia, Universidade Federal do Paraná, Curitiba, Tese para Professor Titular, $130 \mathrm{p}$.

Souza Filho, E.E. 1983. Tectônica da região de Rio Claro-Piracicaba, Domo de Pitanga. In: SBG/ Núcleo São Paulo, Simpósio Regional de Geologia, 4 São Paulo, Atas, 191-196

Tumer, S.; Regelous, M.; Kelley, S.; Hawkesworth, C.; Mantovani, M. 1994. Magmatism and continental break-up in the South Atlantic: high precision ${ }^{40} \mathrm{Ar}-{ }^{39} \mathrm{Ar}$ geochronology. Earth Planet. Sci. Lett., 124:333-348

Washbume, C.W. 1930. Petroleum geology ofthe State of São Paulo - Brazil. São Paulo, Com. Geog. Geol. do Est. S. Paulo, 282 p. (Boletim 22)

Manuscrito A943

Recebido em 18 de outubro de 1997 Revisão dos autores em 12 de janeiro de 1998 Revisão aceita em 14 de janeiro de 1998 